\title{
Comorbidity of Depression and Diabetes Mellitus in University of Gondar Referral Hospital, Gondar, Ethiopia
}

\author{
Deassalegn $\mathrm{K}^{1 *}$, Yemataw $\mathrm{W}^{2}$ and Atinkut $\mathrm{Z}^{3}$ \\ ${ }^{1}$ Department of Psychology, Mizan-Tepi University, Ethiopia \\ ${ }^{2}$ Department of Psychology, University of Gondar, Ethiopia \\ ${ }^{3}$ Department of Psychology, Ambo University, Ethiopia
}

Research Article

Volume 2 Issue 4

Received Date: June 18, 2018

Published Date: July 10, 2018

*Corresponding author: Dessalegn Kassaw Abebaw, Mizan -Tepi University, Mizan, Ethiopia, Tel: +251918042085.

\section{Abstract}

Diabetes is a metabolic disorder with a high worldwide prevalence. It has been reported that diabetic patients are more prone to depression. The purpose of the present study was to assess the prevalence rate of depression among patient with diabetes. Hospital based cross-sectional explanatory design was used. Simple random sampling was employed to recruit 287 diabetes patients from University of Gondar referral hospital, Gondar, Ethiopia. A questionnaire has two sections where the first section collects data on patients' demographic characteristics. The second section, Beck Depression Inventory-II (BDI-II) was used to assess the severity of depression. Descriptive and inferential statistics including percentage, mean and standard deviation, independent sample t-test, point bi-serial and one-way ANOVA were utilized. All data were analyzed using SPSS for Windows version 20. As a result, the general life time prevalence rate of severe depression disorder among diabetes patients was 43\%. In this study, it was revealed that $\operatorname{sex}(\mathrm{t}(285)=-4.29, \mathrm{p}<$ $0.05)$ and medication adherence $(\mathrm{t}(285)=-4.23, \mathrm{p}<0.05)$ do have statistically significant effect on diabetics patients' depression disorder. On the other hand, duration of illness ( $\mathrm{t}(285)=-1.23, \mathrm{p}>0.05)$ and types of diabetes $(\mathrm{t}(285)=0.51$, $\mathrm{p}>0.05$ ) had no statistically significant effect on diabetes patients' depression disorder. Furthermore, ANOVA result shows that diabetics patients' marital status $(\mathrm{F}(3,283)=13.00, \mathrm{p}<0.05)$ and educational status $(\mathrm{F}(4,282)=7.39, \mathrm{p}<$ 0.05 ) had a statistically significant effect on patients' depression disorder. However, age of patients had a statistically insignificant effect on patients' depression disorder $(F(4,282)=0.67, p>0.05)$. Finally, positive correlation were observed between patients' medication adherence and depression $(r=.243, p<0.05)$ although the relationship was weak. To conclude, comorbidity of diabetes and depression is highly prevalent. Therefore, mental health service providers shall regularly screen and treat diabetes patients' clinical depression disorder. Hence, increasing patients' awareness towards diabetes to enhance self-determination through integrated psychological and medical care in the management of diabetes would promote optimal health outcomes.

Keywords: Depression; Diabetes mellitus; Diabetes patients 


\section{Nursing \& Healthcare International Journal}

Abbreviations: BDI-II: Beck Depression Inventory-II; DM: Diabetes mellitus; IDF: International Diabetes Federation; SPSS: Statistical Package for the Social Sciences.

\section{Introduction}

The global prevalence of diabetes is continuously rising. It is estimated that almost 285 million persons are currently suffering from diabetes worldwide, and the number is expected to rise to 438 million by the year 2030; more than $70 \%$ of these individuals reside in developing countries [1]. Diabetes mellitus is the most public endocrine disorder that is characterized by the failure of the body to produce or use insulin properly. Insulin is a hormone produced in the pancreas that allows for transport of glucose (sugar) from the blood to all types of cells in the body [2]. Diabetes mellitus (DM) is a common health problem with serious medical and economic consequences. Between 2010 and 2030, there will be a $69 \%$ increase in numbers of adults with diabetes in developing countries and a $20 \%$ increase in developed countries. The Arab world (North Africa, Middle East, and Gulf area) will have second highest increase in percentage of people with DM in 2030 compared to other parts of the world [3].

Various researchers and professionals have been describing the relationship between diabetes and psychiatric disorder. For example, Collins, Corcoran and Perry [4] claimed that diabetes has been associated with an increased risk of certain psychiatric disorders, particularly depression and anxiety disorders. Individual with diabetes and a comorbid psychiatric disorder are at increased risk of worse management and treatment outcomes than those without a psychiatric disorder. Depression has been associated with hyperglycemia, an increased risk for diabetic complications and other medical illness like coronary heart disease. Diabetic patients with depression are also less likely to adhere to medical treatment [5] and more likely to have higher health care use and expenditures than diabetic patients without depression [6].

Depression is associated with a wide range of negative consequences, including significant worsening of comorbid medical conditions, high mortality risk related to suicide, and socioeconomic burden resulting from functional impairment $[7,8]$. Recently, both diabetes and depression have been associated with premature morbidity and mortality, and when these conditions coexist, the risk for developing comorbidities, complications, suffering of patients, and associated costs escalates $[9,10]$. Therefore, it is relevant to establish the diagnoses of depression and anxiety in the diabetic patient. The presence of undiagnosed anxiety and depression among persons with this condition is a cause of concern since these symptoms hinder the initiation of treatment and allows frustration to build up in patients, thereby contributing to poor clinical outcomes [11]. Anderson, et al. [12] in a meta-analysis of 42 studies, found that patients with either type I or type II diabetes had twice the likelihood of experiencing depression $(11 \%$ and 31\% for major depression and elevated depression symptoms respectively) than a control group of nondiabetic individuals, with the effect generalizing across community and clinical settings. The authors of this finding also concluded that every individual in every three individuals with diabetes has a depression that damages their working, quality of life and diabetic control.

In a more recent systematic review the co-existence of Diabetes mellitus and depression was confirmed [13]. Interestingly rates for undiagnosed depression in Diabetes mellitus patients as per the study conducted by $\mathrm{Li}$, et al. [14] equaled to 45\%. The WHO World Health Survey studied adults aged 18 and above in 60 different countries worldwide and concluded that 1 year prevalence for depression in diabetes was 2\% [15]. A systematic review reported the prevalence of depression in young adults with type 1 diabetes as inconclusive [16]. On the other hand, a meta-analytic review supported claim for raised rate of depression in type 2 diabetes [11]. The International Diabetes Federation (IDF) estimated around 280 million people with Diabetes mellitus in 2010 and this figure is thought to increase to 439 million in 2030 [17]. Diabetes mellitus currently holds the 7th place in cause of death [18]. With depression superimposed in Diabetes mellitus, the mortality rate is likely to increase. Furthermore, there is evidence showing that depression was significantly associated with a wide range of diabetes complications with effect sizes of .17 - .32 [19]. In sum, untreated depression is one of contributing factors for increased mortality rate in Diabetes mellitus.

In many empirical studies, the effects of sociodemographic variables of patients on depression disorder have been studied in developed and developing country intensively. These studies found that being female [20], lower socioeconomic status [21], less education [20,22], younger age [20], being unmarried [23], having a lack of perceived social support [24], smoking status [20,22], duration of diabetes [25], experiencing chronic stressors or negative life events [26] and having multiple chronic 


\section{Nursing \& Healthcare International Journal}

conditions [27] were factors associated with depression among individuals with diabetes.

A study was conducted by Solomon [28] to assess the ten-year trend of diabetes mellitus at University of Gondar teaching referral hospital. His result showed that out of 354,524 patient visited the outpatient department of the hospital during the study period 2000-2009, $1553(4.4 / 1000)$ were diabetes patients, of which $50.1 \%$ type one and $49.9 \%$ type two diabetes mellitus. The documentation of University of Gondar teaching referral hospital in 2014 shows that number of diabetes mellitus patient from $1987-2005$ was 3305 and the document confirm that trends of diabetes mellitus (Figure 1) for the past 18 years has been increasing.

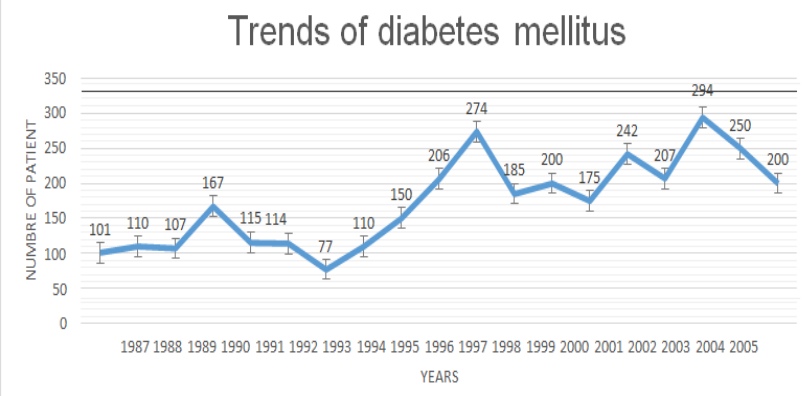

Figure 1: Trends of mental illness in Gondar university referral hospital.

Various researches were conducted to assess depression and their associated factors among diabetic patients in developed countries and comparable results were also documented from other developed countries. However, mental health problems of diabetic patients were not well studied generally in Ethiopia and specifically in Gondar town. Therefore, this study was aimed to assess the prevalence of depression among people with diabetes to initiate early treatment so as to improve clinical outcomes and decrease the associated risk factors. It is the researchers' belief that the findings of this study give relevant information about the comorbidity of diabetes with depression in Gondar town. In addition to the above relevance, it helps to scale up mental health service to chronic illness patients for better outcome of the treatments of diabetes in Ethiopia. Having the above background data, this study tries to address the following research questions.

- What is the prevalence of depression among patients with diabetes in University of Gondar referral hospital?
- Is there statistically significant difference in experiencing depression between groups of demographic variable (age, sex, marital status, educational status, type of diabetes, duration of illness and medication adherence)?

- What is the relationship between depression with some other demographic variables (medication adherence, duration of illness and age)?

\section{Methods and Materials}

\section{Study Design}

The purpose of this study was to assess the prevalence rate of depression among patient with diabetes in university of Gondar referral hospital. To achieve this purpose, hospital based cross-sectional explanatory design was used.

\section{Sampling and Sample Size Determination}

The target population of this study was diabetic patients. According to the documentation of University of Gondar teaching referral hospital in 2014, 3305 of diabetes mellitus patient was registered until 2014. Proportionate stratified sampling was employed to determine the number of participants across sex, age and socio-economic status. Participants were 287 diabetes patients randomly selected at Gondar referral hospital from June 2014 to August 2014. Simple random sampling was used to recruit participants based on the given time frame. In doing so, diabetes patients with different experiences were included in this study including diabetes patients with additional other medical illness, diabetes patients with comma state, patients with gestational diabetes, diabetes patients whose age ranges from 20-90 years old and patients who lived with diabetes less than one year. Besides, involuntary diabetes patients to be involved in this study were excluded.

\section{Data Collection Instruments}

Ultimately, the self-administered questionnaire has two sections where the first section collects data on patients' demographic characteristics. This includes sex, age, marital status, type of diabetes, educational status, medication adherences and duration of illness. The second section of the Beck Depression Inventory (BDI-II) is employed from an instrument developed by Beck, et al. [29]. Its original version (21 items) was introduced in 1961 and its reliability and validity have been established across a broad spectrum of clinical and non-clinical populations. The BDI-II is available in English and has been translated into Amharic language and validated for 


\section{Nursing \& Healthcare International Journal}

use to measure depression. The term "depression" in this study referred to the self-report of depressive symptoms identified in the BDI-II. The format of the BDI-II test is for the participants to select and circle the number beside one of the four phrases listed that best describes their state in the past two weeks including the day the questionnaire is answered. The instrument consists of 21items/statements that are self-reported and takes approximately 15 minutes to complete. The score ranges from 0 - 63 to determine possible degree of depression symptoms. The instrument developers established four groups of scores and classified as the following: "minimal $0-13$, mild 14-19, moderate 20-28, and severe 29-63" [29]. Scores provide an estimate of the overall symptom severity of depression. High scores indicate greater depressive symptoms. We used the most commonly used cut-off scores for BDI of $\geq 16$ to indicate clinical depression [30]. The psychometric properties of the BDIII are sound. Specifically, the BDI-II has a high internal consistency of .91, retest-reliability of .93, and convergent validity with the Hamilton Psychiatric Rating Scale for Depression ( $r=.71$ ) [29].

\section{Pilot Study}

Beside to the reliability and validity, clarity of instruction, items and language simplicity were also checked. The pilot study was conducted in Bahir Dar University Referral Hospital using 50 randomly selected diabetes patients. These 50 diabetes patients were computed by taking $18 \%$ of the general population of the study. Face validity of the English and Amharic version of the questionnaire was assessed by two psychologists from University of Gondar at the same time; the feedback showed that the instruments had good face validity. The instrument translation's consistency was also examined by three language experts from University of Gondar.

The participants of the pilot study were invited to complete the pre-settled questionnaire, which contained the scale along with demographic questions used in the main study. It was clearly stated in the questionnaire and told the participants that confidentiality of information supplied by them would prevail at all times. In addition, the participants were informed that they could give their informed consent freely and voluntarily, and that they had full right to refuse to participate or to withdraw from participation in the study at any stage. Hence, four senior lecturers of psychiatry, sociology, social work and psychology at University of Gondar were asked to comment on any item that they found ambiguous or difficult to understand. These queries did not reveal any major changes that needed to be made to any of the items. The item of the entire completed instrument was evaluated for wording and phrasing as well as for reliabilities to ensure that the resettled questionnaires were suitable for use in the main study.

Based on the comments and suggestions of the experts changes were made in wording of two Amharic versions of Beck Depression Inventory. No changes were made in the numbering and sequencing of the items. No items were deleted for lower rate of reliability. The reliability results of the Amharic version were assessed by Cronbach alpha. In the pilot study, the reliabilities of the tools were found to be 0.91 for Beck Depression Inventory (BDI-II) tool. Finally, the final instrument was developed after wording improvements and was used to gather the main data.

\section{Data Collection Procedure}

After obtaining written approval from University of Gondar to carry out this study, a brief screening for recruitment of participants was conducted by the investigators to identify potential participants in the following manner: every person in the waiting area was asked if he/she is willing to talk to the investigator. If the person agreed to talk to the investigator for possible participation, the attending specialist was asked if that person is scheduled to fill the questionnaire at that visit. If the person agreed to fill the questionnaire, then an informed consent was taken from each patient. Once the consent was signed, verification of inclusion and exclusion criteria took place. The questionnaires required for the study were presented and explained for its completion during this session. The forms and questionnaires that were completed included: 1) demographic and clinical questionnaire to gain information on participant, 2) BDI-II to measure depressive symptoms among participants. Eight data collectors were trained prior to initiation of the study to assist in the recruitment and administration of questionnaires. Re-training of the data collectors who administered the questionnaire took place after the first week of the research study based on the need to clarify certain points in the questionnaire. All participants completed the questionnaires in a private area in the clinic. The data collection process was directly followedup by the supervisors.

\section{Methods of Data Analysis}

Descriptive statistics including percentage, mean and standard deviation were utilized to describe the prevalence of diabetes patients' depression. In addition, independent sample t-test, point bi-serial and one-way ANOVA was utilized to analyze the collected data. All data 
were analyzed using the Statistical Package for the Social Sciences (SPSS) for Windows version 20.

\section{Ethical Consideration}

All subjects signed an informed consent to participate in the study after they were given a verbal and written explanation of the research objectives; they did not receive any economical remuneration. In addition, written permission was obtained from the respective officials of the institutions and organizations where the respondents were recruited based on an official request letter issued by University of Gondar.

\section{Results}

As it is presented in Table 1, out of the total two hundred eighty seven diabetic patients, 161 (56.1\%) were males and 126 (43.9 \%) were females. Besides, with respect to age, most of the participants' age $114(39.2 \%)$ ranges between 20-45 years old, followed by 84 (29.2\%) of participants whose age ranges from 46-55 years old. Also, 88 (30.6\%) of participants were 56-78 years old. Regarding marital status, 148 (51.6 \%), 57 (19\%), 19 (6.6 $\%), 63$ (22\%), were married, divorced, widowed and single respectively. Regarding educational status, most participants $100(34.8 \%)$ were illiterate and 65(22.6\%), $40(13.9 \%), 71(24.7 \%)$ and $11(3.8 \%)$ were primary school, high school, collage /university graduate and post graduate or above completed respectively. In addition, table 1 also shows that the majority of the participants $202(70.4 \%)$ were living with type-2 diabetes mellitus and the other 85 (29.6\%) were living with type-1 diabetes mellitus. Hence, Table 1 shows that 181 (63.1\%) of patients' diabetes duration were between 1-7 years and the other 106 (36.9\%) were between 8-22 years. Finally, with respect to medication adherence, 161 (90.94\%) of patients had higher medication adherence whereas 26 $(9.05 \%)$ of patients had lower medication adherence.

\begin{tabular}{|c|c|c|c|}
\hline Demographic Variable & Categories & Frequency & Percentile \\
\hline \multirow{2}{*}{ Sex } & Male & 161 & 56.1 \\
\hline & Female & 126 & 43.9 \\
\hline \multirow{5}{*}{ Age } & $20-45$ & 114 & 39.2 \\
\hline & $46-55$ & 84 & 29.2 \\
\hline & $56-78$ & 88 & 30.6 \\
\hline & Mean SD & Minimum & Maximum \\
\hline & 48.6212 .78 & 20 & 78 \\
\hline \multirow{4}{*}{ Marital Status } & Single & 63 & 22 \\
\hline & Married & 148 & 51.5 \\
\hline & Divorced & 57 & 19.9 \\
\hline & Widowed & 19 & 6.6 \\
\hline \multirow{5}{*}{ Educational Status } & Illiterate & 100 & 34.8 \\
\hline & Grade 1-8 (Primary school) & 65 & 22.6 \\
\hline & Grade 9-12 Secondary school & 40 & 13.6 \\
\hline & College/ university & 71 & 24.7 \\
\hline & Post graduate and above & 11 & 3.8 \\
\hline \multirow{2}{*}{ Type of Diabetes } & Type 1 & 85 & 29.6 \\
\hline & Type 2 & 202 & 70.4 \\
\hline \multirow{2}{*}{ Duration of illness } & 1-7 year & 181 & 63.1 \\
\hline & 8-22 year & 106 & 36.9 \\
\hline \multirow{2}{*}{ Medication adherence } & Adherence & 161 & 90.94 \\
\hline & Non Adherence & 26 & 9.05 \\
\hline
\end{tabular}

Table 1: Demographic characteristics of the respondent. 


\section{Prevalence of Depression Disorder among Diabetes Patient}

As it is shown in Table 2, out of 287 respondents, 98 (34.1\%), 61 (21.3\%), $74(25.8 \%)$ and $54(18.0 \%)$ of respondents were minimal, mild, moderate and severe level of depression symptomatic respectively. Therefore, the general life time prevalence rate of depression disorder among diabetes patients was 43\% through merging both moderate and severe level of depression.
More specifically, headache, pessimism, and sadness were most frequently reported core symptoms of depression by most of diabetic patients, but suicidal thoughts, stomachache and irritability occur as well.

In order to examine the prevalence of depression symptom, a standardized Beck Depression Inventory was employed and presented as follow:

\begin{tabular}{|c|c|c|}
\hline Depression score & Frequency & Percent \\
\hline Minimum Depression Score (0-13) & 98 & 34.1 \\
\hline Mild Depression Score (14-19) & 61 & 21.3 \\
\hline Moderate Depression Score (20-28) & 74 & 25.8 \\
\hline Severe Depression Score (29-65) & 54 & 18 \\
\hline
\end{tabular}

Table 2: General prevalence rate of depression disorder among diabetes patient.

\section{Comparison of Depression Disorder among Diabetes patients' demographic variable}

As can be seen from Table 3, the independent t-test result showed that there was statistically significant mean difference in experiencing depression disorder between male and female participants $(t(285)=-4.29, p<0.05)$. The mean score of depression disorder for female participants $(M=21.78, S D=9.68)$ was higher than male participants $(M=16.96, S D=9.29)$. This implies that female respondents were more victim of depression disorder than their male respondent counter parts. Moreover, the table 3 also inform us that the mean depression score of patient who are living with diabetes for more than 7 years $(M=20, S D=10.63)$ were higher than the mean depression score of patient who are living with diabetes for less than 7 years $(M=18.54, S D=9.18)$ although the mean difference is not statistically significant $(\mathrm{t}(285)=-1.23, \mathrm{p}>0.05)$. In addition, table 3 also shows that the mean score of depression disorder for type- 1 diabetic patients ( $M=$ 19.52, $\mathrm{SD}=8.8$ ) were higher than the mean score of depression disorder for type- 2 diabetic patients $(M=18.9$, $\mathrm{SD}=10.13)$. However, this difference was not statistically significant (t $(285)=.51, p>0.05)$. Finally, there was a statistically significant difference in experiencing depression disorder between participants with low medical adherents and high medical adherents $(\mathrm{t}(285)=$ $4.23, \mathrm{p}<0.05)$. The mean score of depression for low medical adherence patients $(M=26.7, S D=11.54)$ was greater than the mean score of depression for high medical adherent patient ( $M=18.33, \mathrm{SD}=9.25)$. This result indicates that diabetic patients with low medication adherence were highly vulnerable for experiencing depression disorder than diabetic patients with high medication adherence.

\begin{tabular}{|c|c|c|c|c|c|}
\hline Variable & Category & $\mathbf{N}$ & Mean (SD) & T & p \\
\hline \multirow{2}{*}{ Sex } & Male & 161 & $16.96(9.29)$ & -4.29 & 0 \\
\cline { 2 - 6 } & Female & 126 & $21.78(9.68)$ & & \\
\hline \multirow{2}{*}{ Duration of illness } & $<7$ years & 181 & $18.54(9.18)$ & -1.23 & 0.23 \\
\cline { 2 - 6 } & $>7$ years & 106 & $20.00(10.63)$ & & \\
\hline \multirow{2}{*}{ Type of diabetes } & Type-1 diabetes & 85 & $19.52(8.80)$ & 0.51 & 0.614 \\
\cline { 2 - 6 } & Type-2 diabetes & 202 & $18.9(10.13)$ & & \\
\hline \multirow{2}{*}{ Medication adherence } & Adherent & 261 & $18.33(9.25)$ & -4.23 & 0 \\
\cline { 2 - 6 } & Non adherent & 26 & $26.57(11.54)$ & & \\
\hline
\end{tabular}

Table 3: Mean difference between groups of background variables on depression disorder. 


\section{Relationship between Demographic Variable of Participant and Depression Disorder}

As can be depicted from Table 4, diabetics patients' marital status had a statistically significant effect ( $F$ $(3,283)=13.00, p<0.05)$ on patients' depression disorder in which the mean score of depression disorder for divorced diabetes patients $(\mathrm{M}=24.96, \mathrm{SD}=9.37)$ was higher than widowed $(M=23.05, S D=7.53)$, single $(M=$ 18.96, $\mathrm{SD}=8.03)$ and married $(\mathrm{M}=16.35, \mathrm{SD}=9.37)$ diabetes patients respectively. In addition, diabetics patients' educational status had a statistically significant effect $(F(4,282)=7.39, \mathrm{p}<0.05)$ on patients' depression disorder. Hence, the mean score of depression disorder for illiterate diabetes patients $(M=22.69, S D=10.00)$ was higher than patients whose grade ranges from 1- 8 grade $(M=19.09, S D=8.84)$, college/ university graduated $(M=$ 16.83, $\mathrm{SD}=9.43)$, grade $9-12$ completed $(M=16.10$, $\mathrm{SD}=8.25)$ and post graduate completed $(\mathrm{M}=11.90$, $\mathrm{SD}=8.89$ ) diabetes patients respectively. On the other hand, age of patients $(\mathrm{F}(4,282)=0.67, \mathrm{p}>0.05)$ had no a statistically significant effect on patients' depression disorder.

\begin{tabular}{|c|c|c|c|c|c|}
\hline Variables & Categories & $\mathbf{n}$ & Mean (SD) & $\mathbf{F}$ & $P$-value \\
\hline \multirow{3}{*}{ Age } & $26-45$ years & 114 & $19.27(9.8)$ & \multirow{3}{*}{0.67} & \multirow{3}{*}{0.514} \\
\hline & 46- 55 years & 84 & $18.09(8.75)$ & & \\
\hline & $56-78$ years & 85 & $19.26(1.12)$ & & \\
\hline \multirow{4}{*}{ Marital Status } & Single & 63 & $18.96(8.03)$ & \multirow{4}{*}{13} & \multirow{4}{*}{0} \\
\hline & Married & 148 & $16.35(9.71)$ & & \\
\hline & Divorced & 57 & $24.96(9.37)$ & & \\
\hline & Widowed & 19 & $23.05(7.53)$ & & \\
\hline \multirow{5}{*}{ Educational Status } & Illiterate & 100 & $22.69(10.00)$ & \multirow{5}{*}{7.339} & \multirow{5}{*}{0} \\
\hline & Primary school (1-8 grade) & 65 & $19.09(8.84)$ & & \\
\hline & Secondary School (9-12 grade) & 40 & $16.10(8.25)$ & & \\
\hline & College/ University Graduate & 71 & $16.83(9.43)$ & & \\
\hline & Postgraduate and above & 11 & $11.90(8.89)$ & & \\
\hline
\end{tabular}

Table 4: Mean difference between groups of background variable on depression disorder.

\section{Correlation between Patients' Depression Disorder with Age, Duration of Illness and Medication Adherence}

As it is shown from Table 5 , the results shows that diabetes patients' age $(r=0.026, p>.05)$ and patients' duration of illness ( $r=0.072, p>.05)$ had no relationship with patients' depression symptoms. On the other hand, positive correlation were observed between patients' medication adherence and depression disorder $(r=0.243$, $p<0.05)$ although the relationship was weak.

To see the relationships among depression disorder with patients' age, duration of illness and medication adherence, point bi-serial correlation was computed and presented as follows:

\begin{tabular}{|c|c|c|}
\hline \multirow{2}{*}{ Variable } & Depression Score & \multirow{2}{*}{ P value } \\
\cline { 2 - 2 } & point bi-serial (r) & 0.659 \\
\hline Age & 0.026 & 0.222 \\
\hline Duration of illness & 0.072 & 0 \\
\hline Medication adherence & 0.243 & 0 \\
\hline
\end{tabular}

Table 5: Correlation between Depression with Patients' Age, Duration of Illness and Medication Adherence. *Significant at the 0.05 level

\section{Discussion}

The purpose of this study was to assess the prevalence of depression among patient with diabetes in Gondar referral hospital. In this study, it was found out that the life time prevalence of depression among diabetes patients was $43 \%$. It should be emphasized that high BDIII scores presented in this study are not diagnostic of depression. Rather, high scores are indicative of the presence of depressive symptoms and further clinical 


\section{Nursing \& Healthcare International Journal}

consultation to establish definitive diagnosis of depression is needed. In the literature, there are various studies on the Mexican population that have analyzed this prevalence [31-33]. A similar higher prevalence of depression has been reported among patients with diabetes in previous studies $[4,12,34,35]$. The current study result was also supported by a previous study conducted by Tovilla-Za, et al. [36] on depression and anxiety among 820 patients with type 2 diabetes $\mathrm{s}$ in Mexico. Their result showed that the prevalence rate of depression among type 2 diabetes patients was $48.27 \%$ (95\% CI: 44.48-52.06). In addition, the finding of the current research on depression was also similar with Nepal study who found that the proportion of depression among diabetes patient in Nepal was $40.3 \%$.

The present study result showed that female diabetes patients had found to have higher depression disorder than male patients and the difference was statistically significant. This result yields consistent with previous research findings conducted by Khuwaja, et al. [37] in Pakistan who found that the prevalence of depression for females was higher than males $59.1 \%$ and $22.5 \%$ respectively. Also, this study finding was also similar with other study conducted by Pan, et al. [38] who claimed that the impact of depression in diabetes is thought to be higher in females. A large prospective women cohort conducted in 11 US states found that women with diabetes and comorbid depression had increased mortality rate $(95 \%$ C.I of 3.11$)$. However, it should be pointed out that generally fewer males than females seek treatment for depression. Furthermore, depression in males is more likely to produce irritability, anger or violent behavior rather than depressed mood and thus depression might be missed on screening as irritability/anger are not hallmark features of depression. Correspondingly, this study finding was consistent with various previous studies $[22,26,39,40]$ who found that female diabetic patients had found to have higher depression disorder than their males counter parts. Furthermore, this finding was also consistent with the other studies who reported depression disorder to be significantly higher in diabetic women than in diabetic men [41-44]. Additionally, a cross sectional study in Nigeria conducted by Agbir, et al. [45] reported similar finding with the present study where male to female ratio was 1:3 in experiencing depression among diabetes patients. The finding of this study was also supported by Ghuloum, et al. [46] research who found that depression to be significantly higher in diabetic women $(28 \%)$ than diabetic men (18\%). This could be attributable to genderspecific issues like pregnancy, menstrual cycle changes, post-partum and additional stresses such as responsibilities at work and at home, single parenthood, caring for children and aging parents which could all lead to depression [47].

The result of present study depicted that age of patients had no a statistically significant effect on patients' depression disorder. Contrary to this finding, a Canadian survey suggested that prevalence of depression in diabetic patients is higher in the younger age group (20 - 39 years) as compared to the middle aged groups (40 64 years). This finding has been supported by study conducted by Katon, et al. [22]. In a survey of However, survey in elderly Chinese on Homg Kong found that of that $26 \%$ of elderly had diabetes and elevated depressive symptoms [48]. Correspondingly, the result of this study shows that patients' duration of illness $(r=0.072, p>.05)$ had no relationship with patients' depression symptoms. This result was inconsistent with the results in other studies reporting an association with duration of diabetes $[41,42]$ who found that the duration of diabetes is associated with the development of depression. Increased duration of the disease is known to significantly increase the risk for developing diabetic complications and health care expenditures, as a result such patients are more prone to develop psychological illnesses.

In this study, statistically significant difference had been found between diabetics patients' marital status in experiencing depression disorder where the depression disorder of divorced diabetes patients was higher than widowed, single and married diabetes patients respectively. This finding overlaps with findings from a study by Everson, et al. [21] who found that loneliness is a serious risk factor for mood disorders while marriage and companionship exerts a protective action for anxiety and depression.

In addition, the finding of the present study shows that diabetics patients' educational status had a statistically significant effect on patients' depression disorder where the depression disorder of illiterate diabetes patients was higher than patients whose grade ranges from 1- 8 grade, college/ university graduated, grade $9-12$ completed and post graduate completed diabetes patients respectively. The result of present study was in line with various previous research findings $[21,22,49]$.

In the present study, diabetic patients with low medication adherence were highly depressed than diabetes patients with high medication adherence. This study result yields consistent with previous research findings by Engum, et al. [40]. This study had confirmed that among people with diabetes, those patients with 


\section{Nursing \& Healthcare International Journal}

comorbid common mental disorders were more likely to report lower medication adherence, greater difficulties managing medical care, and more working days lost due to illness. The presence of common mental disorders in people with diabetes was also significantly associated with recent consultations with a family doctor over physical complaints as well as associated with more reported pain. Therefore, comorbidity of diabetes and depression disorder was high. Also, it has been well documented in different literature and research. Similar to other developing countries, in Ethiopia, prevalence of depression among diabetic patients is higher due to different reason including cultural difference and socioeconomic status.

\section{Conclusion and Recommendation}

The prevalence of depression among diabetic patients was higher than reported in other communities and has never been approached before. Being a female, not adherent to anti-diabetic medications, having low educational level and being divorced were significant predictors and are associated with an increased likelihood of developing major depressive disorders.

Depression is significantly associated with diabetes, from incidence to mortality. It may thus be recommended that all patients with diabetes should be screened for depression. Co-occurrence of the two dreaded leads to poor symptom control; greater symptom severity; increased disease burden, disability, work impairment and use of health care services; poor quality of life, substantially higher health care costs. Because of their association with clinical aspects of diabetes care such as diabetes symptom reporting and adherence to diabetes self-care, it is imperative for clinicians to recognize and treat depressive symptoms in patients with diabetes. Therefore, mental health service providers shall regularly screen and treat diabetes patients' clinical psychological distress particularly depression disorder. Hence, increasing patients' awareness to boost selfdetermination and confidence through integrated psychological and medical care in the management of diabetes would promote optimal health outcomes. Along with this, collaborative teamwork between healthcare providers and patients through a compassionate and holistic approach in recognizing early neurotic features is essential to prevent disease comorbidities and mortalities. Besides, early recognition of vulnerable factors associated with depression in people with diabetes is necessary to promote patient adherence and compliance to diabetes control.

\section{Limitations and Future Directions}

There are several limitations of the current study. First, the research was conducted at one center and with the absence of a control group. Second, instruments that applied in this study to collect data did not determine their reliability and validity in Ethiopia context. Third, this research excludes individual with diabetes under age of 20 years old. Finally, since method of design in the study is a cross-sectional study, the causal relationship between the variables weren't explained. Specifically, diabetes management may lead to the development of depressive symptoms and, in turn, depression may worsen diabetic management and complications. The relationship is very likely to be reciprocal and synergistic. Therefore, all these limitations may hinder the generalizability of the study findings. Along with this, the finding of this research implied as further research shall be conducted on the following three areas; first, depression disorder often coexists with other psychological disorders such as acute stress disorder, anxiety disorders, somatization and substance abuse. Second, still the qualitative study has to be conducted on knowledge, belief and attitude of diabetic patients towards the cause, transmission and treatment of diabetes. Finally, replication of this study with a larger and representative sample size would be beneficial to see if similar results are found. The larger the sample size, the greater the credibility and generalizability to the target population.

\section{Conflict of Interest}

The authors declared no conflict of interest and none of them have received direct funding for conducting the study.

\section{Acknowledgements}

The authors would like to genuinely thank the participants and data collectors of the research.

\section{References}

1. Khuwaja AK, Lalani S, Dhanani R, Azam IS, Rafique G, et al. (2010) Anxiety and depression among outpatients with type 2 diabetes: A multi-centre study of prevalence and associated factors. Diabetol Metab Syndr 2: 72. 


\section{Nursing \& Healthcare International Journal}

2. American Diabetes Association (2001) Standards of Medical Care in Diabetes. Diabetes Care 32(1): S1361.

3. Shaw JE, Sicree RA, Zimmet PZ (2010) Global estimates of the prevalence of diabetes for 2010 and 2030. Diabetes Res Clin Pract 87(1): 4-14.

4. Collins M, Corcoran P, Perry (2009) Anxiety and depression symptoms in patients with diabetes. Diabet Med 26(2): 153-161.

5. DiMatteo MR, Lepper HS, Croghan TW (2000) Depression is a risk factor for noncompliance with medical treatment: meta-analysis of the effects of anxiety and depression on patient adherence. Arch Intern Med 160(14): 2101-2107.

6. Egede LE, Zheng D, Simpson K (2002) Comorbid depression is associated with increasedhealth care use and expenditures in individuals with diabetes. Diabetes Care 25(3): 464-470.

7. Kim TS, Jeong SH, Kim JB, Lee MS, Kim JM, et al. (2011) The clinical research center for depression study: baseline characteristics of a korean long-term hospital-based observational collaborative prospective cohort study. Psychiatry Investig 8(1): 18.

8. Greenberg PE, Kessler RC, Birnbaum HG, Leong SA, Lowe SW, et al. (2003) The economic burden of depression in the United States: how did it change between 1990 and 2000? J Clin Psychiatry 64(12): 1465-1475.

9. Lin EH, Rutter CM, Katon W, Heckbert SR, Ciechanowski P, et al. (2010) Depression and advanced complications of diabetes: a prospective cohort study. Diabetes care 33: $264-$ 269.

10. Lin EH, Heckbert SR, Rutter CM, Katon WJ, Ciechanowski P, et al. (2009) Depression and increased mortality in diabetes: unexpected causes of death. Ann Fam Med 7: 414-421.

11. Ali S, Stone MA, Peters JL, Davies MJ, Khunti K (2006) The prevalence of co-morbid depression in adults with Type 2 diabetes: A systematic review and meta analysis. Diabetic Medicine 23(11): 1165-1173.

12. Anderson RJ, Freedland KE, Clouse RE, Lustman PJ (2001) The Prevalence of Comorbid Depression in
Adults With Diabetes: A meta-analysis. Diabetes Care 24(6): 1069-1078.

13. Egede LE, Ellis C (2010) Diabetes and depression: Global perspectives. Diabetes Research and Clinical Practice 87(3): 302-312.

14. Li C, Ford ES, Strine TW, Mokdad AH (2008) Prevalence of depression among US adults with diabetes: findings from the 2006 behavioral risk factorsurveillance system. Diabetes Care 31(1): 105107.

15. Moussavi S, Chatterji S, Verdes E, Tandon A, Patel V, et al. (2007) Depression, chronic diseases, and decrements in health: Results from the World Health Surveys. Lancet 370(9590): 851-858.

16. Johnson B, Eiser C, Young V, Brierley S, Heller S (2012) Prevalence of depression among young people with Type 1 diabetes: A systematic review. Diabet Med 30(2): 199-208.

17. International Diabetes Federation (2009) Diabetes Atlas 4th (Edn.), Brus-sels: International Diabetes Federation.

18. Murphy SL, Xu J, Kochanek KD (2012) Deaths preliminary data for 2010. Natl Vital Stat Rep 61(4): 1-117.

19. Groot MD, Anderson R, Freedland KE, Clouse RE, Lustman PJ (2001) Association of depression and diabetes complications: A meta-analysis. Psychosomatic Med 63(4): 619-630.

20. Egede LE, Zheng D (2003) Independent Factors Associated With Major Depressive Disorder in a National Sample of Individuals with Diabetes. Diabetes Care 26(1): 104-111.

21. Everson SA, Maty SC, Lynch JW, Kaplan GA (2002) Epidemiologic evidence for the relation between socioeconomic status and depression, obesity, and diabetes. J Psychosom Res 53(4): 891-895.

22. Katon W, Von Korff M, Ciechanowski P, Russo J, Lin E, et al. (2004) Behavioral and Clinical Factors Associated With Depression Among Individuals With Diabetes. Diabetes Care 27(4): 914-920.

23. Hanninen JA, Takala JK, Keinanen Kiukaanniemi SM (1999) Depression in subjects with type 2 diabetes. 


\section{Nursing \& Healthcare International Journal}

Predictive factors and relation to quality of life. Diabetes Care 22(6): 997-998.

24. Miyaoka Y, Miyaoka H, Motomiya T, Kitamura S, Asai M (1997) Impact of Socio demographic and diabetesrelated characteristics on depressive state among non-insulin dependent diabetic patients. Psychiatry Clin Neurosci 51(4): 203-206.

25. Talbot F, Nouwen A, Gingras J, Belanger A, Audet J (1999) Relations of diabetes intrusiveness and personal control to symptoms of depression among adults with diabetes. Health Psychol 18(5): 537-542.

26. Fisher L, Chesla CA, Mullan JT, Skaff MM, Kanter RA (2001) Contributors to depression in Latino and European-American patients with type 2 diabetes. Diabetes Care 24(10): 1751-1757.

27. Bell RA, Smith SL, Arcury TA, Snively BM, Stafford JM, et al. (2005) Prevalence and correlates of depressive symptoms among rural older African Americans, Native Americans, and whites with diabetes. Diabetes Care 28(4): 823-829.

28. Solomon M (2014) Epidemiology of diabetes mellitus and barriers of glycemic control in northwest Ethiopia. PhD dissertation summery.

29. Beck A, Steer R, Ball R, Ranieri W (1996) Comparison of Beck Depression Inventories -IA and-II in psychiatric outpatients. J Pers Assess 67(3): 588-597.

30. Lustman PJ, Clouse RE, Griffith LS, Carney RM, Freedl KM (1997) Screening for depression in diabetes using the beck depression inventory. Psychosom Med 59(1): 24-31.

31. Garduno Espinosa J, Tellez Zenteno JF, Hernandez Ronquillo L (1998) Frequency of depression in patients with diabetes mellitus type 2 . Revista de investigacion clinica; organo del Hospital de Enfermedades de la Nutricion 50(4): 287-291.

32. Colunga Rodriguez C, Garcia de Alba JE, Salazar Estrada JG, Angel Gonzalez M (2008) Type 2 diabetes and depression in Guadalajara, Mexico, 2005. Revista de salud publica 10(1): 137-149.

33. Castro Ake GA, Tovar Espinosa JA, Mendoza Cruz U (2009) Association between depression and glycemic control disorder in patients with diabetes mellitus 2 . Revista medica del Instituton Mexicano del Seguro Social 47(4): 377-382.
34. Lustman PJ, Griffith LS, Clouse RE (1988) Depression in adults with diabetes. Results of 5-year follow-up study. Diabetes Care 11(8): 605-612.

35. Grigsby AB, Anderson RJ, Freedland KE, Clouse RE, Lustman PJ (2002) Prevalence of anxiety in adults with diabetes. J Psychosom Res 53(6): 1053-1060.

36. Tovilla Za'rate C, Jua'rez Rojop I, Peralta Jimenez Y, Jime'nez MA, Va'zquez S (2012) Prevalence of Anxiety and Depression among Outpatients with Type 2 Diabetes in the Mexican Population. PLoS ONE 7(5): e36887.

37. Khuwaja AK, Lalani S, Dhanani R, Azam IS, Rafique G, et al. (2010) Anxiety and depression among outpatients with type 2 diabetes: A multi-centre study of prevalence and associated factors. Diabetol Metab Syndr 2: 72.

38. Pan A, Lucas M, Sun $Q$, van Dam RM, Franco OH, et al. (2011) Increased mortality risk in women with depression and diabetes mellitus. Arch Gen Psychiatry 68(1): 42-50.

39. Peyrot M, Rubin RR (1999) Persistence of depressive symptoms in diabetic adults. Diabetes Care 22(3): 448-452.

40. Engum A, Mykletun A, Midthjell K, Holen A, Dahl A (2005) Depression and diabetes: A large population based study of socio- demographic, lifestyle, and clinical factors associated with depression in type 1 and type 2 diabetes. Diabetes Care 28(8): 1904-1909.

41. Almawi W, Tamim H, Al Sayed N, Arekat MR, Al Khateeb GM, et al. (2008) Association of comorbid depression, anxiety, and stress disorders with Type 2 diabetes in Bahrain, a country with a very high prevalence of Type 2 diabetes. Journal of endocrinological investigation 31(11): 1020-1024.

42. Iype T, Shaji SK, Balakrishnan A, Charles D, Varghese AA, et al. (2009) Cognition in type 2 diabetes: Association with vascular risk factors, complications of diabetes and depression. Ann Indian Acad Neurol 12(1): 25-27.

43. Murakumi J (2002) Gender and depression: explaining the different rates of depression between men and women. Perspect Psychol, Springer 27-34. 
44. Piccinelli M, Wilkinsen G (2000) Gender differences in depression: critical review. Br J Psychiatry 177: 486492.

45. Agbir M, Audu M, Adebowale T, Goar SG (2010) Depression among medical outpatients with diabetes: A cross-sectional study at Jos University Teaching Hospital, Jos, Nigeria. Annals of African Medicine 9(1): 5-10.

46. Ghuloum S, Bener A, Burgut FT (2010) Ethnic Differences in Satisfaction with Mental Health Services among Psychiatry Patients. Open Psychiatr J 4: 19-24.
47. Legato MJ, Gelzer A, Goland R, Ebner SA, Rajan S, et al. (2006) Gender-specific care of the patient with diabetes: review and recommendations. Gend Med 3(2): 131-158.

48. Chou KL, Chi I (2005) Prevalence of depression among elderly Chinese with diabetes. International Journal of Geriatric Psychiatry 20(6): 570-575.

49. Khuwaja AK, Kadir MM (2010) Gender differences and clustering patterns of behavioral risk factors for chronic non-communicable diseases: communitybased study from a developing country. Chronic Illn 6(3): 163-170.

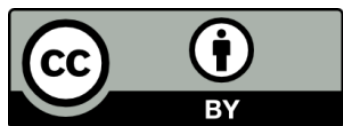

